\title{
Evaluation of Metastatic Cholangiocarcinoma in a Spitz Dog Javad Javanbakht ${ }^{1 *}$, Farhang Sasani ${ }^{1}$, Fariba Khaki ${ }^{1}$, Shahram Jamshidi ${ }^{2}$, Mehdi Aghamohammad Hassan ${ }^{2}$ and Havva Marzban ${ }^{3}$
}

${ }^{1}$ Department of Pathology, Faculty of Veterinary Medicine, Tehran University, Tehran, Iran

${ }^{2}$ Department of Clinical Sciences, Faculty of Veterinary Medicine, Tehran University, Tehran, Iran

${ }^{3}$ Gradaute, Faculty of Veterinary Medicine, Tehran University, Tehran, Iran

\begin{abstract}
A 12-year-old spitz breed dog, with progressive neurologic symptoms including seizures, ataxia, mental depression, walking aimlessly and head pressing was referred to Small Animal Hospital of Veterinary Medicine, the University of Tehran. The dog was received Diazepam prior to examination and diagnosis, whereas it died at first day eventually. In physical examination, there was a firm mass with irregular nodular surface, about 8 $\mathrm{cm}$ in diameter under the skin of mammary glands region. At necropsy, considerable abdominal ascites, several masses with different sizes throughout liver lobes and on intestinal serosa were observed. According to histological adjectives of biliary epithelium due to firm texture of the tumour masses and numerous mitotic figures the tumour was confirmed as cholangiocarcinoma, and immuniohistochemical results for cytokeratin marker demonstrated such diagnosis.
\end{abstract}

Keywords: Immuniohistochemical; Histopathology; Dog; Cholangiocarcinoma; Liver

\section{Introduction}

The liver is a common site of tumour metastasis because of its dual blood supply of the hepatic artery and portal vein [1]. Primary hepatic tumours account for $0.6-1.3 \%$ of all canine neoplasms and include hepatocellular adenoma, hepatocellular carcinoma, cholangiocellular (bile duct) adenoma, and cholangiocellular carcinoma [2]. Other primary hepatic tumours or proliferative lesions are hyperplastic nodules, carcinoids, and sarcomas [3]. Cholangiocarcinoma, or bile duct carcinoma, is a rare primary hepatic neoplasm, and it has a severe morbidity and high mortality [4]. It accounts for $15 \%$ of all primary liver tumours and its incidence rises rapidly, possibly due to the increased incidence of chronic inflammatory liver diseases [3], and more often originates from intrahepatic bile duct epithelium than in extrahepatic bile ducts or the gall bladder [5]. The incidence of cholangiocarcinoma increases with age and most cases occur in animals over 10 years of age; neither a breed nor sex prevalence has been reported in animals $[5,6]$. This short communication describes metastatic cholangiocarcinoma in a spitz dog.

\section{Case Report}

A 12-year-old spitz breed dog, with progressive neurologic symptoms including seizures, ataxia, mental depression, walking aimlessly and head pressing was referred to Small Animal Hospital of Veterinary Medicine, the University of Tehran. The dog was received Diazepam prior to examination and diagnosis, whereas it died at first day eventually.

In physical examination, there was a firm mass with irregular nodular surface, about $8 \mathrm{~cm}$ in diameter under the skin of mammary glands region. At necropsy, considerable abdominal ascites, several masses with different sizes throughout liver lobes (Figure 1) and on intestinal serosa were observed. In addition, the detected masses were multinodular and scattered throughout all liver lobes, and their texture was firm with sizes ranged from 0.5 to $6 \mathrm{~cm}$ in diameter. The crosssection masses were white to gray-white in colour with numerous vessels and foci of necrosis and hemorrhage in central region of nodules. Furthermore, one of the large masses protruded above the capsule of the liver encompassed an umbilical appearance with severe central necrosis and hemorrhage. Two liver lobes were adhered to diaphragm by these masses. In thoracic cavity multiple nodular masses with different sizes and some characteristics of metastatic lesions were recorded.

The tissue samples were collected for histopathological and immunohistochemical examinations.

In liver tissue; diffuse hemorrhages, mild fatty change and diffuse necrosis and apoptosis of hepatocytes were observed. The masses composed of cells resembled to biliary epithelium and organized into tubular and acinar patterns. The neoplastic cells contained cuboidal to columnar with a moderate amount of clear eosinophilic cytoplasm which manifested round to oval vesicular nuclei. Moreover, hyperchromatism, pleomorphism and remarkable mitotic figures were detected. Multiple sites of visible tumoural invasion to surrounding hepatic parenchyma took place as well (Figure 2).

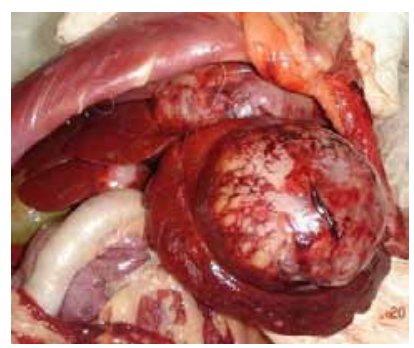

Figure 1: Tumoral mass in liver lobe with central hemorrhage and necrosis.

*Corresponding author: Dr. Javad Javanbakht, Department of Pathology, Faculty of Veterinary Medicine, Tehran University, Tehran, Iran, Tel: +989372512581 E-mail: javadjavanbakht@ut.ac.ir

Received February 01, 2013; Accepted February 28, 2013; Published March 03 , 2013

Citation: Javanbakht J, Sasani F, Khaki F, Jamshidi S, Hassan MA, et al. (2013) Evaluation of Metastatic Cholangiocarcinoma in a Spitz Dog. J Cancer Sci Ther 5: 113-114. doi:10.4172/1948-5956.1000194

Copyright: (c) 2013 Javanbakht J, et al. This is an open-access article distributed under the terms of the Creative Commons Attribution License, which permits unrestricted use, distribution, and reproduction in any medium, provided the original author and source are credited. 
Citation: Javanbakht J, Sasani F, Khaki F, Jamshidi S, Hassan MA, et al. (2013) Evaluation of Metastatic Cholangiocarcinoma in a Spitz Dog. J Cancer Sci Ther 5: 113-114. doi:10.4172/1948-5956.1000194

Tumoural masses compromised epithelial neoplastic cells with round to oval vesicular nuclei, large nucleoli, eosinophilic cytoplasm which arranged in acinar and tubular structures. Conspicuous fibrotic connective tissue was observable amongst neoplastic epithelium. Severe pleomorphism, abundant mitotic figures of neoplastic cells and vascular thrombosis occurred in neoplastic tissues as well. Some of sections were undergone immunohistochemical staining with reactive antibody for cytokeratin (Figure 3).

Metastatic encapsulated foci of cholangiocarcinoma were located in lung parenchyma with same features as well as atelectasis and severe hyperemia (Figure 4).

In kidneys, severe diffuse hyperemia along with tubular necrosis was observed; however, severe parenchymatous and meningeal hyperemia took place in brain tissue.

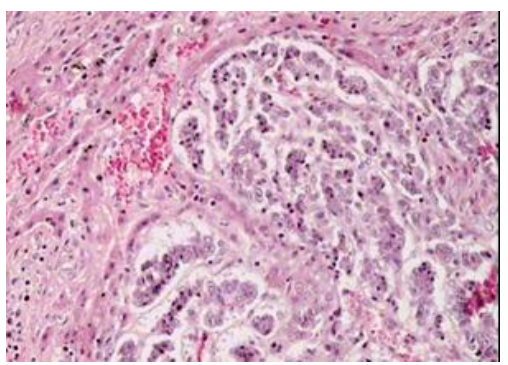

Figure 2: Tumoral foci with ductal and acinar forms of biliary epithelium in liver tissue. H\&E, (x100).

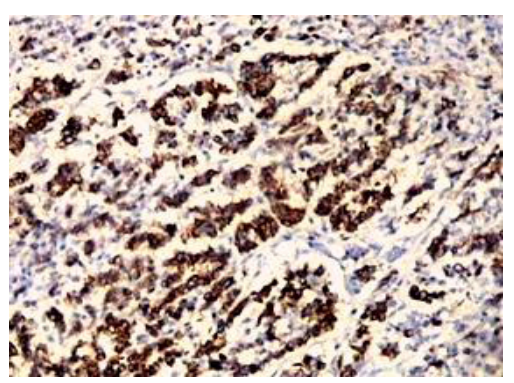

Figure 3: Neoplastic biliary epithelium with abundant cytokeratin in tumoral tissue. IHC staining with cytokeratine marker. (x400)

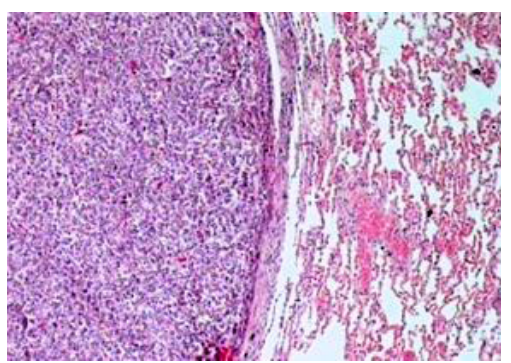

Figure 4: Metastatic foci of cholangiocarcinoma in lung with hyperemia and atelectasia in lung tissue. H\&E, (x40).

\section{Discussion}

In addition to positive immunohistochemial result for cytokeratin marker, the lesion was diagnosed as bile duct carcinoma and neurologic symptoms might be caused by hepatic encephalopathy-induced cholangiocarcinoma.

In comparison with hepatocellular carcinoma, bile duct carcinoma in dog is less common and more malignant, with a higher frequency of metastasis, even though cellular pleomorphism and anaplasia are less obvious than hepatocellular carcinoma [6]. However, the adenoid variant of hepatocellular carcinoma is highly difficult to differentiate from cholangiocarcinoma that in this field immunohistochemisry is of benefit. In one study on 435 epithelial neoplasm cases, hepatocellular carcinoma was one of the CK 7- and CK 20-negative epithelial neoplasms [7]. Cytokeratin (CK) 7 and CK19 expression, present in Hepatic Progenitor Cells (HPCs) and in cholangiocytes but not in normal hepatocytes, has been reported in some hepatocellular carcinomas (HCCs); however, the incidence and relevance of this expression in HCC in Caucasians is not known [8]. CK7, CK19 and CK20 existence in epithelial tissues and most epithelial neoplasms such as bile duct carcinoma $[9,10]$. Microscopic examination of the primary site showed that the tumor in the liver had replaced most of the normal hepatic tissue. Tumor cells formed numerous pleomorphic ducts lined by columnar cells. Many of the ducts contained proteinaceous fluid. The cell nuclei were oval and their long axes parallel to the long axis of the columnar cell. There were large areas of hemorrhage in the tumor. According to histological adjectives of biliary epithelium due to firm texture of the tumour masses and numerous mitotic figures the tumour was confirmed as cholangiocarcinoma, and immuniohistochemical results for cytokeratin marker demonstrated such diagnosis.

\section{References}

1. Straw RC (1996) Hepatic tumors. In: Small Animal Clinical Oncology. Withrow SJ McEwen EG: 48-252. WB Saunders, Philadelphia, PA.

2. Cullen JM, McLachlan NJ (2001) Liver, biliary system, and exocrine pancreas In: Thompson's Special Veterinary Pathology, McGavin MD, Carlton WW Zachary JF.

3. Bergman JR (1985) Nodular hyperplasia in the liver of the dog: an association with changes in the Ito cell population. Vet Pathol 22: 427-438.

4. Lai GH, Sirica AE (1999) Establishment of a novel rat cholangiocarcinoma cell culture model. Carcinogenesis 20: 2335-2340.

5. Ciftci MK, Ortatati M, Avki S (1998) Bir kedide kolangiseluler karsinom olgusu Veterinary Bill Dergisi 14: 91-96.

6. Patnaik AK, Hurvitz Al, Lieberman PH (1980) Canine hepatic neoplasms: clinicopathologic study. Vet Pathol 17: 553-564.

7. Chu P, Wu E, Weiss LM (2000) Cytokeratin 7 and Cytokeratin 20 expression in epithelial neoplasms: A survey of 435 cases. Mod Pathol 13: 962-972.

8. Durnez A, Verslype C, Nevens F, Fevery J, Aerts R, et al. (2006) The clinicopathological and prognostic relevance of cytokeratin 7 and 19 expression in hepatocellular carcinoma. A possible progenitor cell origin. Histopathology 49: 138-151.

9. Rullier A, Le Bail B, Fawaz R, Blanc JF, Saric J, et al. (2000) Cytokeratin 7 and 20 expression in cholangiocarcinomas varies along the biliary tract but still differs from that in colorectal carcinoma metastasis. Am J Surg Pathol 24: 870-876.

10. Shimonishi T, Miyazaki K, Nakanuma Y (2000) Cytokeratin profile relates to histological subtypes and intrahepatic location of intrahepatic cholangiocarcinoma and primary sites of metastatic adenocarcinoma of liver. Histopathology 37: 55-63. 